\title{
Ontology-Enabled E-gov Service Configuration: An Overview of the OntoGov Project
}

\author{
Efthimios Tambouris ${ }^{1}$, Stelios Gorilas ${ }^{1}$, Gregory Kavadias $^{1}$, Dimitris Apostolou ${ }^{2}$, \\ Andreas Abecker ${ }^{3}$, Ljiljana Stojanovic $^{3}$, and Gregory Mentzas ${ }^{4}$ \\ ${ }^{1}$ Archetypon S.A., 236 Sygrou Av., Athens, 176-72, Greece \\ \{tambouris, sgorilas, gkavadias\} @archetypon.gr \\ ${ }^{2}$ Planet Ernst \& Young, Apollon Tower, Louise Riencourt 64, Athens 115-23, Greece \\ dapost@planetey.com \\ ${ }^{3}$ FZI - Forschungszentrum Informatik an der Universität Karlsruhe, \\ Haid-und-Neu-Str. 10-14, D-76131 Karlsruhe, Germany \\ \{abecker, stojanovic\}afzi.de \\ ${ }^{4}$ National Technical University of Athens, 9 Iroon Politexniou Str., Zografou 157-80, \\ Greece \\ gmentzas@softlab.ntua.gr
}

\begin{abstract}
For electronic government initiatives to succeed, in addition to modernising the front office, attention should be also paid in order to streamline, reorganise and support the back-office processes of public administrations that provide public services to citizens. Furthermore, actions should be taken to limit the loss of critical knowledge assets during the life cycle of electronic government services. In this paper, the OntoGov project is outlined aiming to develop, test and validate a semantically-enriched (ontology-enabled) platform that will facilitate the consistent composition, re-configuration and evolution of electronic government services.
\end{abstract}

\section{Introduction and Motivation}

Electronic government (e-Gov) is a major priority in Europe today and European governments are clearly committed to embracing related initiatives [1]. One of the primary objectives of e-Gov is to increase productivity through higher efficiency and to offer better quality services and innovation based on information technology [2].

For e-Gov initiatives to succeed, in addition to modernising the front office by offering public services via Internet portals, attention should be also paid to streamlining, re-organising and supporting the back-office processes of public administrations that provide services to citizens. Furthermore, actions should be taken to limit the loss of critical knowledge assets during the life cycle of e-Gov services.

The main objective of this paper is to outline the OntoGov project that aims to overcome the above mentioned problems by developing, testing and validating a semantically-enriched, ontology-enabled platform that will facilitate the consistent composition, re-configuration and evolution of e-Gov services. 
The remaining of this paper is organised as follows. In Section 2, state of the art and related projects are reviewed. In Section 3, an overview of the OntoGov project is presented. Finally, in Section 4 a summary is provided along with the plans for future work.

\section{State of the Art and Related Projects}

\subsection{State of the Art in Electronic Government}

State of the art in e-Gov includes realising the concept of one-stop e-Gov [3][4], especially together with the idea of service portals with life-situation navigation [5]. The basic ideas of one-stop e-Gov are already well-developed and their technical realisation on top of state-of-the-art IT and web service technology is dealt with sufficiently in some running or upcoming projects. What is not solved sufficiently, are the methodological and technological prerequisites as well as the back-office processes, which help turning one-shot investments into one-stop approaches into sustainable, long-term endeavours which can be maintained effectively and consistently over a longer period of time. This idea requires on one hand a higher level of re-configurability and on-the-fly changes of services - which is not provided by today's web service technology; and on the other hand a well-understood and technically supported knowledge logistics along the horizontally (many implementing sites) and vertically (several levels of decision-making) highly distributed decision and implementation processes of e-Gov services - which is not covered at all at the moment, but can reuse some concepts and approaches from corporate knowledge management (KM) where scenarios like KM in supply-chain integration, KM in virtual organizations, or KM integrations with Business Intelligence for Management Information Systems addresses similar kinds of problems.

Since we consider ontology-based, semantically enriched models a central topic in this area, we briefly state that the use of semantic technologies in e-Gov is still not state-of-the-art. The e-Gov scenario is in some respects a more obvious and promising application field for ontologies than many commercial areas, since legislative knowledge is by nature already "formal" to a big extent, it is by definition shared by many stakeholders, and its formalization should pay off, because it could be reused in many applications. Nevertheless, there are only very few, yet far developed ontology projects in e-Gov. Typical is the IST FP5 SmartGov project that developed an ontology for the public sector [6] and the e-POWER project [7] which employed deep knowledge modelling techniques for "heavy-weight" inferences for, e.g. consistency checks, harmonisation or consistency enforcement in legislation. Although such projects convincingly show in principle the feasibility of ontology approaches in e-Gov, they did not address the matter of service implementation or service integration. 


\subsection{State of the Art in Ontology-Based Web Technology}

The current web is a huge collection of information, but does not yet support processing this information, i.e., using the computer as a computational device. Recent efforts around UDDI, WSDL, and SOAP try to lift the web to a new level of service. Software programs can be accessed and executed via the web based on the idea of web services. Though such approaches are first steps into the direction of a web populated by services, the current Web Service description languages still have numerous limitations, e.g.:

- low expressiveness (e.g., no support for types and subsumption and no ability to express constraints);

- no ontology support for expressive data modelling;

- only simple message request/reply patterns that ignore application logic aspects in terms of processes.

Proposals like ebXML and UBL (Universal Business Language) of OASIS have been underlining that existing proposals are more or less purely syntactical and fail to address semantic / ontological issues. Furthermore, standards for process definitions as well as exchange sequence definitions have been proposed such as WSFL, XLANG, BPSS, BPML and WSCL.

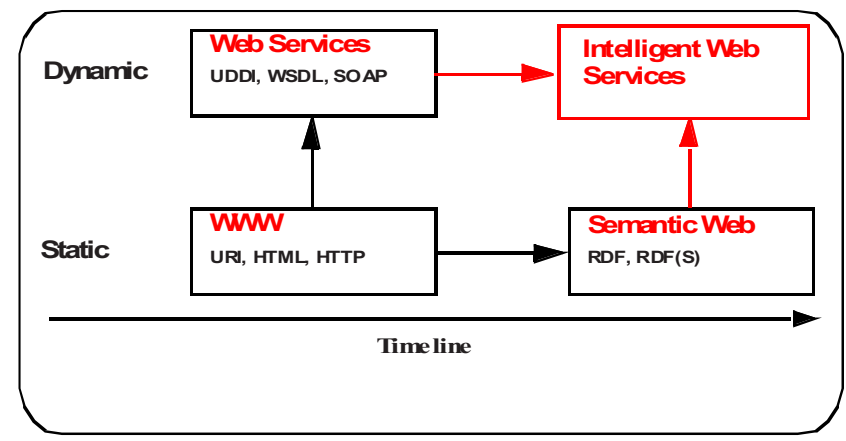

Fig. 1. Semantic Web enabled Web Services

Tim Berners-Lee, the inventor of the current WWW, coined the vision of a Semantic Web in which background knowledge is stored on the meaning or content of Web resources through the use of machine-processable metadata. The Semantic Web will bring meaningful structure to the content of Web pages. Ontologies define a vocabulary with semantically well-defined terms and, thus, enabling precise service descriptions on which mechanisms for automated discovery, composition, negotiation and reconfiguration can be built on. Semantic Web enabled Web Services (or Intelligent Web Services) bring together the Web Service and the Semantic Web ideas. They provide mechanization in service identification and discovery, configuration, comparison, and combination.

Semantic Web enabled Web Services are currently being investigated in many places. Two of the most important initiatives are the OWL-S proposal for a Web 
service description language from the US, and the WSMO (Web Service Modeling Ontology) in Europe developed for the SWWS and DIP European projects.

\section{OntoGov Overview}

The OntoGov project will specify, develop and deploy a holistic framework and a supporting platform to improve public service provision by enabling semantically rich representation, evolution and refinement of public processes and services to citizens and businesses.

Currently, in an increasing number of public authorities throughout Europe the public service provision model is comprised of the following parts (Figure 2):

- Data Sources in Back Office

- Processes in Back Office (most of these are now automated or are in the process of automation - this is denoted as "Application Logic" in Figure 2)

- Broker where public services are jointed up. This can be automated, semiautomated or performed manually. In the case of a central point this broker is located at a central public authority (usually a ministry)

- Communication channels handling the interface with citizens and businesses

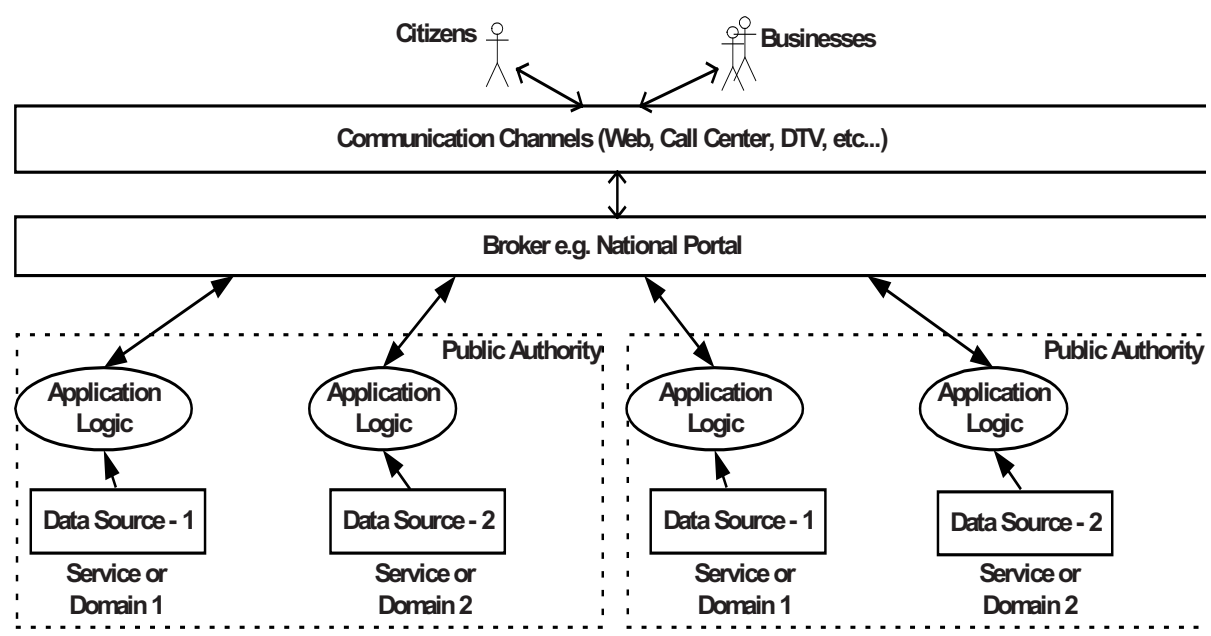

Fig. 2. Current service provision model

The envisaged framework is depicted in Figure 3. The main idea behind the proposed framework is that the existing service provision mechanisms are extended to incorporate, and to a certain degree be driven by, semantics.

The new Semantic Provision Model consists of several components. In a bottomup approach the work to be done within this project consists of the following steps: 


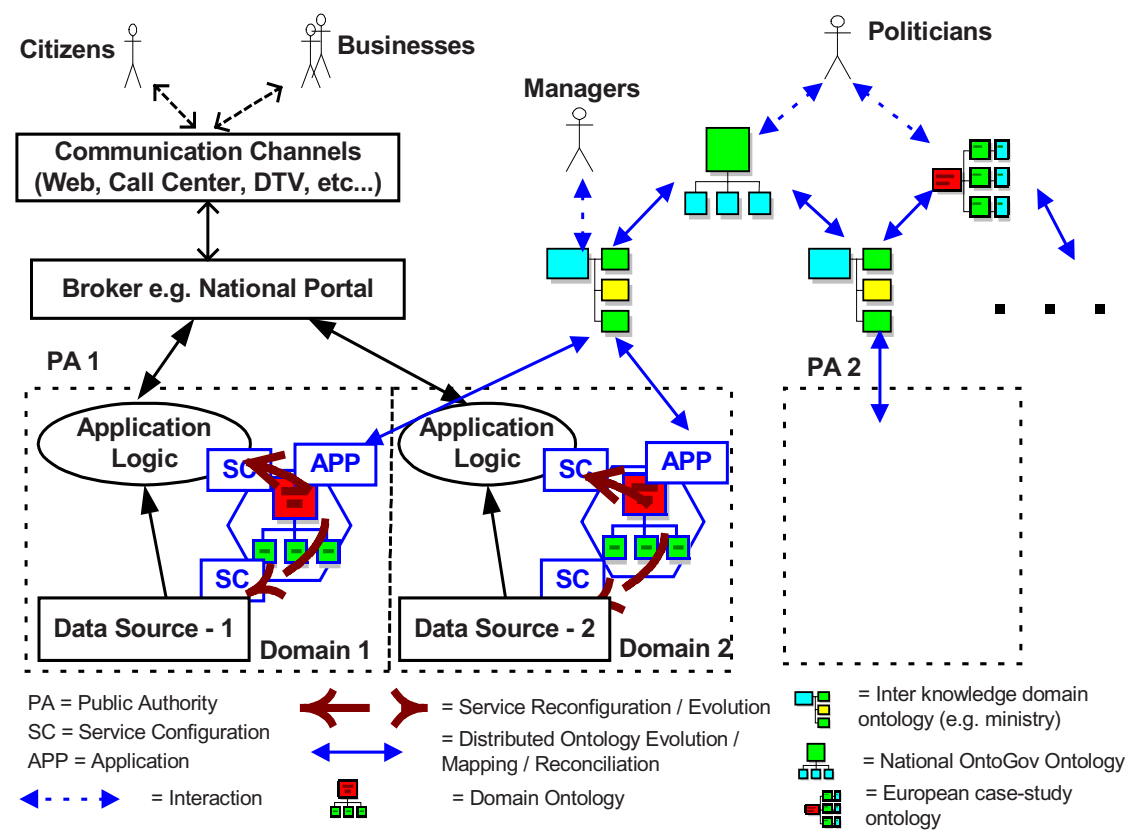

Fig. 3. OntoGov service provision model

- Work at a conceptual level (towards the Framework for Semantic Service Provision)

1. Identify services (knowledge domains) of particular importance e.g. issuing birth certificate, VAT payment etc.

2. For each service derive a Semantic Framework (the Domain Ontology) for describing the respective knowledge domain by re-using the findings of the previous step.

3. From the Domain Ontologies, identify and extract the common concepts and properties that shall form the National Semantic Framework (National Ontology). At this stage this can be realised by defining the necessary mapping/reconciliation/etc mechanisms that will lead to a hierarchy of OntoGov processes.

4. For some specific services derive a pilot Pan-European Semantic Framework (Pan-European Ontology for that Domain) e.g. Pan-European Ontology for issuing a Birth Certificate.

- Work at a technical level (towards the supporting platform)

5. Develop the Service configuration modules for automated or semiautomated communication between Domain Ontology, Data Sources and Application Logic 
6. Develop all interfaces for different stakeholders (citizens, managers, politicians, etc.) at various levels (local authorities, national focal points, panEuropean level).

\section{Epilogue}

In this paper, an overview of the OntoGov project is presented. OntoGov is a 30months research and development project aiming to develop, test and validate a semantically-enriched (ontology-enabled) platform that will facilitate the consistent composition, re-configuration and evolution of e-Gov services. Our next steps are to proceed with a detailed specification, development, deployment and evaluation of this platform.

Acknowledgements. This work was carried out as a part of the OntoGov project (OntoGov IST-2002-507237), which is partially funded by the European Commission under the IST programme. The OntoGov consortium consists of the following partners: Planet Ernst \& Young (EL), FZI (D), Archetypon S.A. (EL), Indra Sistemas S.L. (S), Barcelona (S), Amaroussion (EL), FHSO (CH) and Swiss Federal Chancellery $(\mathrm{CH})$.

\section{References}

1. European Commission, eEurope 2005 Action Plan. Available at http://europa.eu.int/ information_society/eeurope/2005/all_about/action_plan/index_en.htm

2. "e-Gov and the European Union" Speech by Mr Erkki Liikanen (Member of the European Commission, responsible for Enterprise and the Information Society) at the Internet and the City Conference "Local eGovernment in the Information Society" Barcelona - 21 March 2003.

3. Hagen M., Kubicek H. (editors), "One-Stop-Government in Europe: Results of 11 national surveys", University of Bremen, Bremen, Available at http://infosoc2.informatik.unibremen.de/egovernment/cost/one-stop-government/home.html, 2000.

4. Tarabanis K. and Peristeras V. "Requirements for Transparent Public Services Provision amongst Public Administrations", in EGOV 2002, LNCS 2456, pp. 330-337, 2002.

5. Tambouris E. and Wimmer M. "Online one-stop government: a single point of access to public". Chapter of the book Digital Government: Strategies and Implementations in Developed and Developing Countries, which has been scheduled to be published by Idea Publishing Group, USA in 2004 (ed. Dr. Wayne Huang).

6. Adams N. et al. "Towards an Ontology for Electronic Transaction Services", Proceedings of ES 2002, Cambridge, UK, December 2002.

7. E-POWER Project Home Page, Available at http://www.lri.jur.uva.nl/ epower/ 